\title{
Clinical Influence of Sodium-Glucose Cotransporter 2 (SGLT2) Inhibitors for Cardiovascular and Renal Points of View
}

Bando $\mathrm{H}^{1,2^{*}}$

${ }^{1}$ Medical Research / Tokushima University, Tokushima, Japan

${ }^{2}$ Japan low carbohydrate diet promotion association (JLCDPA), Kyoto, Japan

Corresponding Author: Hiroshi Bando, MD, PhD, FACP

Address: Tokushima University /Medical Research, Nakashowa 1-61, Tokushima 770-0943 Japan; Tel: +81-90-31872485; E-mail: pianomed@bronze.ocn.ne.jp

Received date: 22 January 2020; Accepted date: 25 January 2020; Published date: 30 January 2020

Citation: Bando H. Clinical Influence of Sodium-Glucose Cotransporter 2 (SGLT2) Inhibitors for Cardiovascular and Renal Points of View. Diab Res Open Access. 2020 Jan 30;2(S1):9-13.

Copyright (C) 2020 Bando H. This is an open-access article distributed under the Creative Commons Attribution License, which permits unrestricted use, distribution, and reproduction in any medium, provided the original work is properly cited.

\begin{abstract}
Diabetes has been a major medical and health problem worldwide. Adequate glycemic control has shown a clinically beneficial effect for long-term prognosis, with recent anti-diabetic agents. There are some mega studies concerning Sodium-glucose cotransporter 2 (SGLT2) inhibitors. They are i) Canagliflozin cardioVascular Assessment Study (CANVAS), ii) Canagliflozin and Renal Events in Diabetes with Established Nephropathy Clinical Evaluation (CREDENCE), iii) Dapagliflozin Effect on CardiovascuLAR Events (DECLARE) -TIMI 58, iv) Empagliflozin Cardiovascular Outcome Event Trial in Type 2 Diabetes Mellitus Patients-Removing Excess Glucose (EMPA-REG OUTCOME) study. Current topics of SGLT2 inhibitors for cardiovascular and renal points of view were described.
\end{abstract}

\section{Keywords}

Sodium-Glucose Cotransporter 2 (SGLT2) Inhibitors; Canagliflozin Cardio-Vascular Assessment Study (CANVAS); Canagliflozin and Renal Events in Diabetes with Established Nephropathy Clinical Evaluation (CREDENCE); Dapagliflozin Effect on CardiovascuLAR Events (DECLARE) -TIMI 58; The Empagliflozin Cardiovascular Outcome Event Trial in Type 2 Diabetes Mellitus Patients-Removing Excess Glucose (EMPA-REG OUTCOME) Study

Diabetes has been a major medical and health problem worldwide. The usefulness of strict glycemic control in early-stage after the onset of diabetes has been reported in UKPDS33, UKPDS34 and UKPDS80 [1-3]. Adequate glycemic control has shown a beneficial effect on long-term prognosis 10-20 years later. On the other hand, strict glycemic control is said to have little benefit for patients with type 2 diabetes, who has diabetes for more than 10 years. These data can be found in three large clinical trials which are
ACCORD, ADVANCE, and VADT [4-6]. The similar results have been observed in rather recent reports which are long-term follow-up studies [7-9]. Furthermore, there was a J-DOIT3 study, in which strict control of blood pressure, lipids and glucose have been continued and compared with conventional therapy. In this RCT study, significant improvement of cardiovascular prognosis was not found [10].

Regarding the target of glycemic control, the 
Citation: Bando H. Clinical Influence of Sodium-Glucose Cotransporter 2 (SGLT2) Inhibitors for Cardiovascular and Renal Points of View. Diab Res Open Access. 2020 Jan 30;2(S1):9-13.

American College of Physicians (ACP) has published a statement, in which the target HbA1c would be at 7$8 \%$ in almost the diabetic patients [11]. The reason for the comment would be from a higher risk of hypoglycemia in previous oral medicine and the reduced risk of hypoglycemia in currently indicated anti-diabetic agents. Recently, highly safer oral medications have become widespread, including Dipeptidyl peptidase-4 (DPP-4) inhibitors and Sodium-glucose cotransporter 2 (SGLT2) inhibitors. Authors and colleagues have reported the clinical efficacy of SGLT2 inhibitor for glucose variability in rather a short period [12]. Current topics on these drugs are described in this article.

There are some mega studies concerning SGLT2 inhibitors. They are i) Canagliflozin cardioVascular Assessment Study (CANVAS), ii) Canagliflozin and Renal Events in Diabetes with Established Nephropathy Clinical Evaluation (CREDENCE), iii) Dapagliflozin Effect on CardiovascuLAR Events (DECLARE) -TIMI 58, iv) Empagliflozin Cardiovascular Outcome Event Trial in Type 2 Diabetes Mellitus Patients-Removing Excess Glucose (EMPA-REG OUTCOME) study.

Concerning the SGLT2 inhibitor, this was known as CREDENCE Clinical Trials [13]. Patients with T2DM and albuminuric CKD were assigned to receive canagliflozin. They included 4401 subjects with 63 years old on average. Subjects were divided randomly into two groups, which were the canagliflozin group and the placebo group. The relative risk of primary outcome was 30\% lower in the former group (Hazard ratio (HR) 0.70 [95\% CI: 0.59 to 0.82 ]). A doubling of creatinine level or death from renal causes was lower by $34 \%$ (HR 0.66 [95\% CI 0.53 to 0.81$]$ ), and the relative risk of end-stage kidney disease was lower by 32\% (HR o.68 [95\% Cl 0.54 to o.86]). The former group showed a lower risk of cardiovascular death, myocardial infarct, and stroke (HR o.80), hospitalization from heart failure (HR o.61). In contrast, no significant differences were found in rates of amputation (HR 1.11) or fracture (HR 0.98).

As to the effects of SGLT2 inhibitors in renal failure, there was a systematic review and meta- analysis of randomized, controlled, cardiovascular or kidney outcome trials [14]. From data of 2085 records, four studies had met the inclusion criteria. They included three SGLT2 inhibitors, which were empagliflozin (EMPA-REG OUTCOME) [15,16], canagliflozin (CANVAS Program and CREDENCE) [17], and dapagliflozin (DECLARE-TIMI 58) [18,19]. Among them, there included 38,723 subjects, 335 endstage kidney disease, and 252 dialysis or transplantation or died of kidney disease. By the administration of SGLT2 inhibitors, the risk of required dialysis was reduced by 33\% (HR o.67). Further, the risk of end-stage kidney disease and acute kidney injury was reduced (HR 0.65, and 0.75 , respectively). Consequently, SGLT2 inhibitors decreased the risk of dialysis, transplantation, or death due to kidney disease. These results suggest the substantive evidence of SGLT2 inhibitors for preventing major kidney outcomes in T2DM.

Furthermore, a systematic review and metaanalysis was reported to assess the efficacy and safety of SGLT2 inhibitors for T2DM and CKD [20]. Patients were selected as estimated glomerular filtration rate (eGFR) $<60 \mathrm{~mL} / \mathrm{min} / 1.73 \mathrm{~m} 2$. As a result, data was collected from 7363 participants in 27 studies. SGLT2 inhibitors decreased HbA1c by $0.29 \%$ with body weight, blood pressure, and albuminuria. SGLT inhibitors reduced the risk of cardiovascular death, nonfatal myocardial infarction or nonfatal stroke (RR, o.81) and heart failure (RR, o.61). Moreover, SGLT inhibitors reduced the declined slope of eGFR a year and decreased the risk of the composite renal outcome (HR 0.71) [20]. Consequently, SGLT2 inhibitors can reduce the risk of cardiovascular and renal exacerbation in T2DM and CKD, without evidence of additional safety concerns.

According to the primary analysis of the CANVAS, canagliflozin showed a beneficial effect on cardiovascular and renal outcomes in T2DM [17,13]. However, it showed an increased risk of lower extremity amputation. Consequently, the secondary analyses were conducted [21]. There were 187 (1.8\%) participants with atraumatic lower extremity amputations (minor $71 \%$, major $29 \%$ ), and the rates were 6.30 vs 3.37 / 1000 participant-years with two 
Citation: Bando H. Clinical Influence of Sodium-Glucose Cotransporter 2 (SGLT2) Inhibitors for Cardiovascular and Renal Points of View. Diab Res Open Access. 2020 Jan 30;2(S1):9-13.

groups of canagliflozin vs placebo (HR 1.97 [95\% CI 1.41 to 2.75]). The risk was similar to those of ischemic and infective etiologies and to $100 \mathrm{mg}$ and $300 \mathrm{mg}$ doses. Anticipated risk factors for amputation were identified, including a prior history of amputation (HR 21.31 [95\% CI 15.40 to 29.49]), peripheral vascular disease and neuropathy. However, there was no specific etiological mechanism or at-risk subgroup for canagliflozin.

Furthermore, the study of the risk for lower limb amputations with SGLT-2 inhibitors were conducted [22]. A total of 27 trials were collected and investigated. They include Canagliflozin, Dapagliflozin, Empagliflozin, Ertuglifozin and analyzed cases were 29407 cases in the SGLT2 group and 21556 cases in the control group. The overall incidence of peripheral artery disease (PAD) was increased with SGLT-2 inhibitors, in which the Mantel-Haenszel odds ratio (MH-OR) with 95\% Confidence Interval was 1.26 (1.04, 1.52). The increase in risk was statistically significant only with canagliflozin. MH-OR for amputation in the cardiovascular safety trials with SGLT-2 inhibitors was 1.22 [0.59-2.52] (not significant). Consequently, there is no reason to believe that empagliflozin or dapagliflozin increases the risk of either PAD of lower limb amputations. Canagliflozin could be associated with a specific risk, which needs to be further investigated [22].

There was a study for whether SGLT2-I are associated with a higher risk of lower-extremity amputation than DPP-4 inhibitors and sulphonylureas [23]. It was a retrospective cohort study, from 328,150 applicants aged 18-64. As a result, the estimated hazard of lower-extremity amputation was increased in SGLT2 inhibitors compared to DPP-4 inhibitors (adjusted Hazard Ratio (aHR) 1.69, 95\% CI 1.20-2.38). In contrast, it was a similar value (aHR 1.02) or nonmetformin, non-SGLT2 inhibitors (aHR 1.02).

In summary, recent topics for the effects of SGLT2 inhibitors on cardiovascular and renal function were introduced. We hope that this description will help future diabetes care and research.

\section{References}

[1] UK Prospective Diabetes Study (UKPDS) Group. Intensive blood-glucose control with sulphonylureas or insulin compared with conventional treatment and risk of complications in patients with type 2 diabetes (UKPDS 33). Lancet. 1998 Sep 12;352(9131):837-53. [PMID: 9742976]

[2] UK Prospective Diabetes Study (UKPDS) Group. Effect of intensive blood-glucose control with metformin on complications in overweight patients with type 2 diabetes (UKPDS 34). Lancet. 1998 Sep 12;352(9131):854-65. [PMID: 9742977]

[3] Holman RR, Paul SK, Bethel MA, Matthews DR, Neil HA. 10-year follow-up of intensive glucose control in type 2 diabetes. $\mathrm{N}$ Engl J Med. 2008 Oct o9;359(15):1577-89.

[4] Action to Control Cardiovascular Risk in Diabetes Study Group, Gerstein HC, Miller ME, Byington RP, Goff DC Jr, Bigger JT, Buse JB, Cushman WC, Genuth S, Ismail-Beigi F, Grimm RH Jr, Probstfield JL, Simons-Morton DG, Friedewald WT. Effects of intensive glucose lowering in type 2 diabetes. N Engl J Med. 2008 Jun 12;358(24):2545-59. [PMID: 18539917]

[5] ADVANCE Collaborative Group, Patel A, MacMahon S, Chalmers J, Neal B, Billot L, Woodward M, Marre M, Cooper M, Glasziou P, Grobbee D, Hamet P, Harrap S, Heller S, Liu L, Mancia G, Mogensen CE, Pan C, Poulter N, Rodgers A, Williams B, Bompoint S, de Galan BE, Joshi R, Travert F. Intensive blood glucose control and vascular outcomes in patients with type 2 diabetes. N Engl J Med. 2008 Jun 12;358(24):256o-72. [PMID: 18539916]

[6] Duckworth W, Abraira C, Moritz T, Reda D, Emanuele N, Reaven PD, Zieve FJ, Marks J, Davis SN, Hayward R, Warren SR, Goldman S, McCarren M, Vitek ME, Henderson WG, Huang GD; VADT Investigators. Glucose control and vascular complications in veterans with type 2 diabetes. $\mathrm{N}$ Engl J Med. 2009 Jan 8;36o(2):129-39. [PMID: 19092145]

[7] Zoungas S, Chalmers J, Neal B, Billot L, Li Q, Hirakawa Y, Arima H, Monaghan H, Joshi R, Colagiuri S, Cooper ME, Glasziou P, Grobbee D, Hamet P, Harrap S, Heller S, Lisheng L, Mancia G, Marre M, Matthews DR, Mogensen CE, Perkovic V, Poulter N, Rodgers A, Williams B, MacMahon S, Patel A, Woodward M; ADVANCE-ON Collaborative Group. 
Citation: Bando H. Clinical Influence of Sodium-Glucose Cotransporter 2 (SGLT2) Inhibitors for Cardiovascular and Renal Points of View. Diab Res Open Access. 2020 Jan 30;2(S1):9-13.

Follow-up of blood-pressure lowering and glucose control in type 2 diabetes. N Engl J Med. 2014 Oct 9;371(15):1392-406. [PMID: 25234206]

[8] Hayward RA, Reaven PD, Wiitala WL, Bahn GD, Reda DJ, Ge L, McCarren M, Duckworth WC, Emanuele NV; VADT Investigators. Follow-up of glycemic control and cardiovascular outcomes in type 2 diabetes. N Engl J Med. 2015 Jun 4;372(23):2197206. [PMID: 260396oo]

[9] ACCORD Study Group. Nine-Year Effects of 3.7 Years of Intensive Glycemic Control on Cardiovascular Outcomes. Diabetes Care. 2016 May;39(5):701-8. [PMID: 26822326]

[10] Ueki K, Sasako T, Okazaki Y, Kato M, Okahata S, Katsuyama H, Haraguchi M, Morita A, Ohashi K, Hara K, Morise A, Izumi K, Ishizuka N, Ohashi Y, Noda M, Kadowaki T; J-DOIT3 Study Group. Effect of an intensified multifactorial intervention on cardiovascular outcomes and mortality in type 2 diabetes (J-DOIT3): an open-label, randomised controlled trial. Lancet Diabetes Endocrinol. 2017 Dec;5(12):951-64. [PMID: 29079252]

[11] Qaseem A, Wilt TJ, Kansagara D, Horwitch C, Barry MJ, Forciea MA; Clinical Guidelines Committee of the American College of Physicians. Hemoglobin A1c Targets for Glycemic Control With Pharmacologic Therapy for Nonpregnant Adults With Type 2 Diabetes Mellitus: A Guidance Statement Update From the American College of Physicians. Ann Intern Med. 2018 Apr 17;168(8):569-76. [PMID: 29507945]

[12] Ebe K, Bando H, Muneta T, Bando M, Yonei Y. Remarkable Improvement of Glucose Variability by Sodium-Glucose Cotransporter 2 (SGLT2) Inhibitors using Continuous Glucose Monitoring (CGM). Diabetes Case Rep. 2019 Jan 28;4(1):139.

[13] Perkovic V, Jardine MJ, Neal B, Bompoint S, Heerspink HJL, Charytan DM, Edwards R, Agarwal R, Bakris G, Bull S, Cannon CP, Capuano G, Chu PL, de Zeeuw D, Greene T, Levin A, Pollock C, Wheeler DC, Yavin Y, Zhang H, Zinman B, Meininger G, Brenner BM, Mahaffey KW; CREDENCE Trial Investigators. Canagliflozin and Renal Outcomes in Type 2 Diabetes and Nephropathy. N Engl J Med. 2019 Jun 13;380(24):2295-306. [PMID: 3099026o]

[14] Neuen BL, Young T, Heerspink HJ, Neal B, Perkovic V, Billot L, Mahaffey KW, Charytan DM, Wheeler DC, Arnott C, Bompoint S. SGLT2 inhibitors for the prevention of kidney failure in patients with type 2 diabetes: a systematic review and metaanalysis. The Lancet Diabetes \& Endocrinology. 2019 Nov 1;7(11):845-54.

[15] Zinman B, Inzucchi SE, Lachin JM, Wanner C, Ferrari R, Fitchett D, Bluhmki E, Hantel S, Kempthorne-Rawson J, Newman J, Johansen OE, Woerle HJ, Broedl UC. Rationale, design, and baseline characteristics of a randomized, placebo-controlled cardiovascular outcome trial of empagliflozin (EMPAREG OUTCOME $\left.{ }^{\mathrm{TM}}\right)$. Cardiovasc Diabetol. 2014 Jun 19;13:102. [PMID: 24943000]

[16] Zinman B, Wanner C, Lachin JM, Fitchett D, Bluhmki E, Hantel S, Mattheus M, Devins T, Johansen OE, Woerle HJ, Broedl UC, Inzucchi SE; EMPA-REG OUTCOME Investigators. Empagliflozin, Cardiovascular Outcomes, and Mortality in Type 2 Diabetes. N Engl J Med. 2015 Nov 26;373(22):2117-28. [PMID: 26378978]

[17] Neal B, Perkovic V, Mahaffey KW, De Zeeuw D, Fulcher G, Erondu N, Shaw W, Law G, Desai M, Matthews DR. Canagliflozin and cardiovascular and renal events in type 2 diabetes. New England Journal of Medicine. 2017 Aug 17;377(7):644-57.

[18] Wiviott SD, Raz I, Bonaca MP, Mosenzon O, Kato ET, Cahn A, Silverman MG, Zelniker TA, Kuder JF, Murphy SA, Bhatt DL, Leiter LA, McGuire DK, Wilding JPH, Ruff CT, Gause-Nilsson IAM, Fredriksson M, Johansson PA, Langkilde AM, Sabatine MS; DECLARETIMI 58 Investigators. Dapagliflozin and Cardiovascular Outcomes in Type 2 Diabetes. N Engl J Med. 2019 Jan 24;380(4):347-57. [PMID: 30415602] [19] Mosenzon O, Wiviott SD, Cahn A, Rozenberg A, Yanuv I, Goodrich EL, Murphy SA, Heerspink HJL, Zelniker TA, Dwyer JP, Bhatt DL, Leiter LA, McGuire DK, Wilding JPH, Kato ET, Gause-Nilsson IAM, Fredriksson M, Johansson PA, Langkilde AM, Sabatine MS, Raz I. Effects of dapagliflozin on development and progression of kidney disease in patients with type 2 diabetes: an analysis from the DECLARE-TIMI 58 randomised trial. Lancet Diabetes Endocrinol. 2019 Aug;7(8):6o6-17. [PMID: 31196815]

[20] Toyama T, Neuen BL, Jun M, Ohkuma T, Neal B, Jardine MJ, Heerspink HL, Wong MG, Ninomiya T, Wada T, Perkovic V. Effect of SGLT2 inhibitors on cardiovascular, renal and safety outcomes in patients with type 2 diabetes mellitus and chronic kidney 
Citation: Bando H. Clinical Influence of Sodium-Glucose Cotransporter 2 (SGLT2) Inhibitors for Cardiovascular and Renal Points of View. Diab Res Open Access. 2020 Jan 30;2(S1):9-13.

disease: A systematic review and meta-analysis.

Diabetes Obes Metab. 2019 May;21(5):1237-50.

[PMID: 30697905]

[21] Matthews DR, Li Q, Perkovic V, Mahaffey KW, de Zeeuw D, Fulcher G, Desai M, Hiatt WR, Nehler M, Fabbrini E, Kavalam M, Lee M, Neal B. Effects of canagliflozin on amputation risk in type 2 diabetes: the CANVAS Program. Diabetologia. 2019 Jun;62(6):926-38. [PMID: 30868176]

[22] Dicembrini I, Tomberli B, Nreu B, Baldereschi GI, Fanelli F, Mannucci E, Monami M. Peripheral artery disease and amputations with Sodium-Glucose coTransporter-2 (SGLT-2) inhibitors: A meta-analysis of randomized controlled trials. Diabetes Res Clin Pract. 2019 Jul;153:138-44. [PMID: 31150722]

[23] Yang JY, Wang T, Pate V, Gower EW, Crowley MJ, Buse JB, Stürmer T. Sodium-glucose co-transporter-2 inhibitor use and risk of lower-extremity amputation: Evolving questions, evolving answers. Diabetes Obes Metab. 2019 May;21(5):1223-36. [PMID: 30697897]

Keywords: Sodium-Glucose Cotransporter 2 (SGLT2) Inhibitors; Canagliflozin Cardio-Vascular Assessment Study (CANVAS); Canagliflozin and Renal Events in Diabetes with Established Nephropathy Clinical Evaluation (CREDENCE); Dapagliflozin Effect on CardiovascuLAR Events (DECLARE) -TIMI 58; The Empagliflozin Cardiovascular Outcome Event Trial in Type 2 Diabetes Mellitus Patients-Removing Excess Glucose (EMPA-REG OUTCOME) Study 